\title{
REVIEW OF BUS DRIVERS' OCCUPATIONAL STRESS AND STRESS PREVENTION
}

\author{
MICHIEL A. J. KOMPIER \\ TNO Health \& Prevention, Work and Organizational Psychology, University of Nÿmegen. The Netherlands \\ VITTORIO DI MARTINO* \\ International Labour Office, Conditions of Work and Welfare Facilities Branch, Working Conditions and \\ Environment Department, Geneva, Switzerland
}

\begin{abstract}
SUMMARY
Although heterogeneous in methodology and content, 32 studies from 13 countries on bus drivers' work and health are similar in their conclusions. Bus-driving - characterized by high demands, low control and low support - can be regarded as a classic example of high-strain occupation, with high risks of physical and mental occupational illhealth, leading to absenteeism and to decreased productivity of employees and enterprises. Several recommendations - some of them already being implemented by bus companies - are presented in order to reduce work stress in bus drivers. They relate to: (a) ergonomics of the bus cabin, (b) job rotation and 'combination jobs', (c) timetables, shift schedules and quality of break periods, and (d) the social work environment and management style. Stress monitoring and stress reduction is not merely a technical process based on a technical analysis and on the simple 'straightforward' realization of recommendations and findings. It relates to changing and improving organizations and organizational processes. Such organization changes can best be obtained through a stepwise and participative approach. There are indications that those companies that invest in preventive measures receive their rewards.
\end{abstract}

KEY WORDS-bus drivers; stress; prevention; stepwise participative approach

The aim of this article is to answer three related questions: (a) how can the results of various studies on the work, stress and health of bus drivers be summarized? (b) which preventive measures are indicated in order to provide a more balanced relationship between the workload of the driver and his coping capacity? and (c) how can a preventive approach to reducing work stress best be achieved? In order to answer these questions a review of the literature was conducted and an inventory was made of preventive measures and recommendations.

\section{OVERVIEW OF STUDIES}

Table 1 examines 32 studies from 13 countries. Most studies are on city bus drivers, some address

Address for correspondence: Michiel A. J. Kompier, Work and Organizational Psychology, University of Nÿmegen, P.O. Box 9107, 6500 HE Nÿmegen, The Netherlands.

*'The opinions expressed in this article are the sole responsibility of the author and do not necessarily reflect the position of the ILO. rural and intercity drivers. This overview is not exclusive but it covers the most important studies from three decades and is representative for this field of study.

There is a large variety in studies and study design. Fifteen of the 32 studies compare bus drivers with other employees: office workers, conductors, non-drivers, blue-collar workers, taxi drivers, employees of a brewery, white-collar employees, employees of a printing office or national statistics.

Fifteen studies concern sickness absenteeism, work disablement (sometimes including rehabilitation) and turnover. Twelve authors use broad questionnaires to study health effects and constraints in the working situation. Four ergonomic studies are conducted, while several questionnaires deal with ergonomic problems. Thirteen studies investigate psychophysiological reactions of bus drivers (eg blood pressure, adrenaline, cholesterol) or employ physical examinations. Two authors performed an analysis of the accident risk of bus drivers.

CCC 0748-8386/95/040253-10

(C) 1994, International Labour Organization, Geneva. This article is based on a forthcoming ILO Manual on Stress Prevention for Bus Drivers (1995). 
Table 1-Important studies on bus drivers' work and health

\begin{tabular}{|c|c|c|c|c|c|}
\hline & Authors & ype of study & Country & Year & Sample population \\
\hline 1. & Anderson & 4 & California & 1992 & 130 drivers \\
\hline 2. & Aronsson & 2 & Sweden & 1982 & 4554 bus and subway drivers \\
\hline 3. & Backman & 1,4 & Finland & 1983 & $\begin{array}{l}1597 \text { professional drivers, inc. } \\
\text { bus drivers }\end{array}$ \\
\hline 4. & Brooks & 6 & UK & 1979 & 30 bus drivers \\
\hline 5. & Courtney \& Wong & 3 & Hong Kong & 1985 & Hong Kong buses \\
\hline 6. & Davis \& Lowe & 3 & UK & 1987 & London buses \\
\hline 7. & Duffy \& McGoldrick & 1 & UK & 1990 & 376 bus drivers \\
\hline 8. & Erlam & 2 & UK & 1982 & 12,639 bus drivers \\
\hline 9. & Feickert \& Forrester & 1,2 & UK & 1983 & 289 bus drivers \\
\hline 10. & Felnemeti \& Boon-Heckl & 4 & Austria & 1985 & 18 bus drivers \\
\hline 11. & Garbe & 2 & Germany & 1983 & 775 bus drivers \\
\hline 12. & Gardell et al. & $1,2,4$ & Sweden & 1982 & $\begin{array}{l}1422 \text { bus, tram, train and } \\
\text { guard workers }\end{array}$ \\
\hline 13. & Grosfeld & 1,2 & Netherlands & 1993 & 2050 bus drivers \\
\hline 14. & De Haan et al. & 1,2 & Netherlands & 1978 & 1252 bus drivers \\
\hline 15. & Holme et al. & 1,4 & Norway & 1977 & $\begin{array}{l}98 \text { bus drivers }(14,000 \text { other } \\
\text { employees) }\end{array}$ \\
\hline 16. & Kompier & $1,2,3$ & Netherlands & 1988 & 4180 bus drivers \\
\hline 17. & Kompier & 5 & Review & 1985 & \\
\hline 18. & Meifort et al. & 1,2 & Germany & 1983 & 300 bus drivers, 300 tram drivers \\
\hline 19. & Meijman et al. & 2 & Netherlands & 1982 & 135 ex-bus drivers \\
\hline 20. & Morris et al. & 4 & UK & 1966 & 413 bus drivers \\
\hline 21. & Mulders et al. & 4 & Netherlands & 1982 & 12 bus drivers \\
\hline 22. & Netterstrom \& Laursen & 2,4 & Denmark & 1981 & 1396 bus drivers \\
\hline 23. & Nijhuis \& Bullinga & 1,2 & Netherlands & 1991 & 120 bus drivers \\
\hline 24. & Oortman-Gerlings et al. & 1,3 & Netherlands & 1985 & 8 buses \\
\hline 25. & Oversloot et al. & 1,2 & Netherlands & 1982 & 655 bus drivers \\
\hline 26. & Pikus \& Tarannikova & 4 & Soviet Union & 1975 & 930 bus drivers and 312 ex-drivers \\
\hline 27. & Pokorny et al. & 6 & Netherlands & 1987 & 990 bus drivers' accidents \\
\hline 28. & Ragland et al. & 2,4 & USA & 1987 & 1500 bus drivers \\
\hline 29. & Reimann & 2,4 & Germany & 1981 & 28 bus drivers \\
\hline 30. & Rissler \& Aronsson & 4 & Sweden & 1983 & 41 bus drivers \\
\hline 31. & Rosconi et al. & 2,4 & Italy & 1975 & 200 bus drivers \\
\hline 32. & Winkleby et al. & 5 & Review & 1988 & \\
\hline
\end{tabular}

1, Questionnaire health outcomes and or working situation.

2 , Study on absenteeism, work disability (and rehabilitation), turnover.

3, Ergonomic study.

4, Biomedical study or physical examination.

5 , Literature review.

6, Accident study.

These studies, although heterogeneous in methodology and contents, are similar in their conclusions:

1. Sickness absenteeism and the risk of disablement are significantly higher as compared to other professional groups or national statistics. ${ }^{11,12,16}$ Bus drivers who have to leave their job for medical reasons do so at a younger age than comparable groups of employees. The main conditions leading to disablement relate to the back, tendons and joints, mental disorders and cardiovascular disease.

2. Musculoskeletal disorders appear to be a major work-related health problem in bus drivers. ${ }^{1,3,9,12,16,25}$ Frequently reported complaints relate to the back, neck and shoulders, and the knees. Many studies indicate strong 
feelings of fatigue, tension and mental overload among bus drivers. ${ }^{9,12,14,16,18,25}$ Also, problems regarding the stomach and intestines ${ }^{3,9,12}$ and sleeping problems, especially related to early shifts, are typical for bus drivers. 716,18

3. There are high psychophysiological costs involved in driving a bus. Several authors studied the psychophysiological costs of this occupation, during work and leisure. Most of them indicate relatively high blood pressure among bus drivers. ${ }^{12,15,20,26,28,29}$ In an early and classic study, Morris et al. ${ }^{20}$ demonstrated bus drivers' blood pressures to be higher than those of their conductors. Mulders et al. ${ }^{21}$ demonstrated relatively high levels of urine-adrenaline in bus drivers. Gardell et al. ${ }^{12}$ showed that bus drivers, when under time pressure, are characterized by high cortisol levels. Many authors report more diseases of the heart and blood vessels among bus drivers in comparison to other professional groups.

4. Many types of buses have obvious deficiencies in design and construction. ${ }^{16}$ These ergonomic deficiencies relate to the lack of uniformity and freedom of movement, and to the driving seat, the steering wheel and pedals. Vibration levels are a major occupational hazard. ${ }^{24}$ The diameter of the fixed steering wheel $(550 \mathrm{~mm})$ is too large, and a large fixed steering wheel has many advantages. As a consequence of these shortcomings, drivers are unable to adjust themselves adequately to the seat, the steering wheels and pedals to accommodate individual body characteristics. Moreover, many drivers report 'a bad layout of the work station' and bad illumination, blinding and reflection, which seem to be primarily related to night driving, bad weather conditions and neon lights. $3,9,16,18$

5. Major constraints in the working situation relate to references $7,12,14,16,18$ and 29 :

(a) High and conflicting demands. The driver's task is mentally demanding because drivers have to cope with conflicting task demands. The company and the public want the driver to maintain good contact with passengers and to be service-oriented. These are also important aspects for job satisfaction. This demand for service often conflicts with the need to keep to a tight schedule in dense traffic and the demand to drive safely in accordance with traffic regulations. (b) Low autonomy and support. Whichever alternative the driver adopts, he or she cannot resolve the basic problem of conflicting demands. This is a 'low autonomy' situation and an important cause of work stress. Although often bus drivers characterize themselves as 'boss in their own bus', this 'power' is greatly restricted. To a large extent they work isolated from colleagues and superiors. Often bus drivers complain about not knowing what management is at and not getting enough information and support from middle and top management.

(c) Threats and violence. Physical harm is increasingly becoming an occupational risk for bus drivers, especially in large cities and during night work. Sometimes drivers are robbed or assaulted.

(d) Work schedules and the work-leisure relationship. Irregular working hours are a major inconvenience. Classic problems concern dayto-day assignments, which mean great uncertainty about the time and place of the next day's work. Other problems concern split shifts, slowly rotating and backward rotating (lateday-early) schedules, the length of the working week and working day, the number, length and quality of break periods, the daily rest between two consecutive workings 'days', and the possibility of taking days off.

The results of these 32 studies are summarized in Fig. 1.

Bus-driving appears to be an occupation with high risks for health and well-being. It may also be concluded that these problems concerning health and well-being are to a large extent work-related, that is, caused by work characteristics, since:

1. Comparisons with other occupational groups generally show more psychological and musculoskeletal problems and higher absence and disability figures among bus drivers.

2. Meaningful and plausible relations have been demonstrated between work factors and the nature and size of the health problems.

3. To a large extent, 32 studies from a large number of countries yield comparable results.

Interventions and preventive measures seem indicated in order to provide a more balanced relationship between the workload of the driver and his or her coping capacity. 
(1) WORK

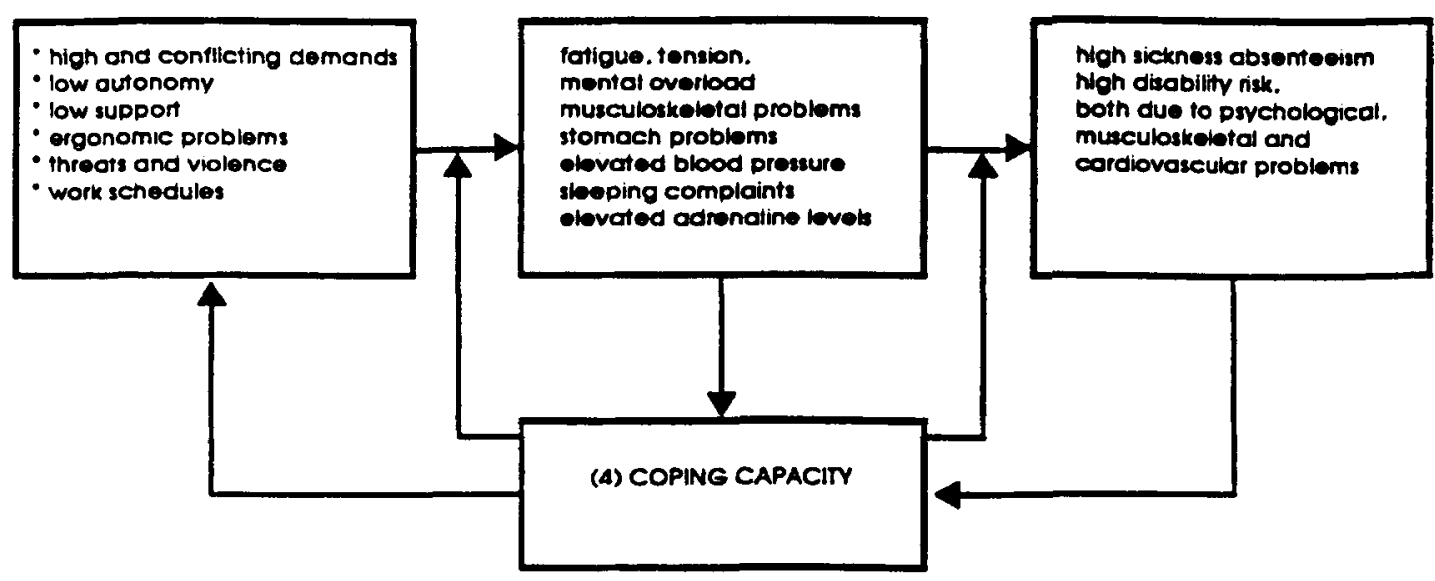

Fig. 1-Work, stress and health of bus drivers

\section{PREVENTION AND INTERVENTION}

There is a clear distinction between the large number of studies that demonstrate the adverse health effects of the bus drivers' occupation and the small amount of documented prevention projects in bus companies. In Table 1, only the study by Grosfeld ${ }^{13}$ can be characterized as an intervention project. This study, however, has not yet been finished. This difference might suggest that companies have no experience in stress prevention. However, that would be too negative an image of the preventive policies and experiences of various bus companies. Many of those interventions are not described and evaluated in articles or book chapters. Some of the interventions and preventive measures, together with recommendations based on the first part of this article, are discussed below.

\section{Ergonomics}

Important measures affecting the design and construction of cabin components are listed in Table 2. Consequently, cabin components will become more adapted to individual anthropometric characteristics, such as height and weight.

\section{Job rotation and 'combination jobs'}

'Combi jobs' refer to the combination of the bus driver's task with other non-driving (eg clerical or mechanics) tasks. In practice, the successful introduction of combination jobs in bus companies is difficult. This might be due to differences in 'professional status' between the different tasks and to the fact that alternative positions for bus drivers in bus companies are scarce. Although on a

Table 2--Ergonomic recommendations

\section{Driving seat}

The range of adjustments of many seats needs to be enlarged. The vertical range should be $100 \mathrm{~mm}$; the range fore-after should be more than $150 \mathrm{~mm}$ Adjustable springs

There should be a lumbar support, adjustable in height and thickness

\section{Steering wheel}

The diameter should be less than $500 \mathrm{~mm}$

The steering wheel should be adjustable in vertical direction and fore-after

The steering wheel should have an independent adjustment of the angle of inclination: 15-32 degrees

3. Pedals

The pedals should have equal angles

The range of the angles should be less than 25 degrees

4. Dashboard

Uniform design, easily accessible and user-friendly, clear colours, etc

5. Working space

Most cabins are too small; drivers need some moving space!

More effective heating and cooling systems

\section{Training}

With respect to these recommendations, training of drivers is clearly indicated 
general basis this approach is hard to manage, it has proved to be very successful in cases of individual drivers. Some recent examples of "combi jobs' are given by Bailer and Trankle. ${ }^{33}$

\section{Timetables, shift schedules and quality of break periods}

Several measures can be recommended in order to attain a more balanced relation between work and rest, both during and between working days. Some of these have already been introduced in several companies (Table 3 ).

\section{Social work environment and management style}

Table 4 lists some important recommendations with regard to the social work environment. Some of these principles have already been introduced in various companies. ${ }^{34-37}$

\section{ORGANIZATIONAL COMMITMENT, COOPERATION AND A STEPWISE APPROACH}

Stress monitoring and stress reduction is not merely a technical process, based on a technical analysis and on the simple 'straightforward' realization of recommendations and findings. Instead it relates to changing and improving organizations and organizational processes. The promotion of healthy working conditions is in the first place the (legal) responsibility of the employer. Often this can be stimulated by trade unions, work councils and health and safety committees, who
Table 3-Recommendations for work and rest schedules and timetable

1. There should be enough time to reduce task conflicts

2. Work should be organized in periods of several (maximum 4) consecutive days within the same shift

3. Avoid split shifts

4. Regular assignments instead of 'day-to-day' assignments

5. Choose forward rotation: early-day-late

6. Two days off between blocks of working days

7. Guaranteed opportunities to take days off

8. A break following every 2 working hours

can try to get stress placed on the company agenda.

Stress prevention projects in bus companies and in other branches of industry in various countries $^{38,39}$ have demonstrated that a successful approach is participatory and stepwise. A participatory approach means an active role for all the parties involved: (top) management, middle managements, employees, trade unions and, when available, the personnel department and the company doctor. Such an approach also presupposes that all parties consider it worthwhile to work together in reducing work stress. If there is no real commitment from these parties, then there is a high risk that a stress project will not be successful and will fail in its ultimate objectives (ie fewer complaints and absenteeism, an improved working environment, a better and more efficient work organization). Five steps constitute a systematic, stepwise approach to reduce stress: preparation, problem analysis, choice of measures, implementation and evaluation.

Table 4-Recommendations for social work environment

1. Divide the total driving staff into fixed groups of 10-20 drivers with one fixed supervisor

2. Introduce a system of work consultation for these groups, and take comments from the drivers seriously

3. Introduce a more supportive style of leadership, train supervisors and managements in their new behaviours

4. Give opportunities for (re)education

5. Provide special facilities for older drivers and for drivers with health problems

6. Promote a timely and active rehabilitation policy ('social medical guidance')

7. Make individual work resumption plans, in cooperation with management, the company doctor, the driver, the personnel department

8. Teach management to be clear: let them explain when something is not possible

9. Stimulate non-work contacts, eg social evenings, sporting activities, etc

10. Stimulate a corporate identity

11. Maintain a proper information flow in the company; people want to known 'what is going on'

12. Take into account wishes of individual drivers

13. On certain lines, high-risk transport calls for two persons on the bus instead of one 


\section{First step: Preparation}

Before starting a work stress project, commitment and sometimes organizational facilities (eg a budget) should be created. This step is directed at a clear determination of aims, planning and financial means. To put stress on the company's agenda one can focus on several data to reveal stress signals: absenteeism figures, high turnover or work disablement rates, number of accidents, data concerning working overtime, backlogs in taking days off, etc. Also, interview with bus drivers and (middle) management can give global indications on possible causes and consequences of stress.

Such data can play an important role in getting different parties involved. Other arguments that can stimulate cooperation between groups within the company can be found in the possible outcomes of the project: more effective work organization and a motivated workforce. Improving working conditions and 'human capital' often requires investments. However, in many cases these investments will lead to profits. By diminishing the absenteeism rate, productivity rates can be improved. There also will be fewer costs related to the introduction and training of new drivers to replace those drivers leaving the company for medical reasons.

\section{Second step: Problem analysis}

In this step it is decided in more detail which, in this specific company, are the main stressors. Of course, the major stressors are well known (Fig. 1), but there are differences between companies, for example regarding shift schedules, timetables, leadership style, the ergonomic quality of the bus driver's cabin, and the amounts of threats and violence.

To monitor these stressors the checklist presented in Table 5 can be used for group interviews or in work consultation. Also, several questionnaires can be used. ${ }^{40}$

Furthermore, health indicators such as absenteeism figures, work disability and health complaints can be studied in more detail. Special risk groups, for instance elderly drivers, can be identified.

\section{Third step: Choice of measures}

In the third step the focus is on building an integrated action programme, based on workers' participation and commitment. In most cases, in order to obtain optimum results, a programme for prevention of and intervention in work stress should combine several measures that have been mentioned, based on Levi's ${ }^{41}$ three strategies in order of preference:

1. Eliminate or modify the stress-producing situation

2. Change the work to fit the individual characteristics of the bus driver

3. Strengthen the driver's coping capacity

Companies should be careful not to opt for temporary solutions. Some programmes start up then rapidly come to an end. In such cases the old situation often reoccurs. They should also be careful not to concentrate too much on single stressors and partial solutions. This limited approach has been demonstrated in several companies. Some enterprises only try to change the work to fit the individual characteristics of the employee. Other companies start by concentrating on the least preferred path: strengthen the driver's resilience to stress, for instance through physical exercise or relaxation techniques. ${ }^{42}$ It can be argued that this is "putting the cart before the horse'. In the case of ergonomic problems, the first priority should be to improve the conditions, for instance by installing a chair that meets ergonomic standards. Teaching people how to sit on a bad chair is not very productive. As for dealing with passengers, this only can be done properly when the timetable permits it.

Changing one stressor might affect other stressors. This is what often happens when partial solutions are introduced. Improvements for one group might even mean deterioration for another. In some companies, the introduction of less demanding 'senior schedules' meant that younger drivers had to drive the more demanding shifts. In other companies, the advantages of introducing special bus lanes (less traffic congestion) were cancelled out by a more demanding timetable.

\section{Step 4: Implementation}

The success of the implementation is largely dependent on good preparation and communication between the 'change agents', the employees whose working situation is involved and the organizational staff. These 'change agents' can be management representatives, a personnel manager or a company doctor, etc. 
Table 5-Checklist to monitor stress risks in bus drivers

l. Job content

1.1. Is it possible to drive without problems with aggressive or troublesome passengers?

Yes No (if no, which lines give problems?)

1.2. Are drivers sufficiently well informed to provide a service to passengers?

\section{Ergonomics}

Driving seat

2.1. Vertical range of adjustment $>100 \mathrm{~mm}$ ?

2.2. Range fore-after $>150$ ?

Steering wheel

2.3. Diameter $<500 \mathrm{~mm}$ ?

2.4. Adjustable in vertical direction and fore-after?

2.5. Independent adjustment of angle of inclination 15-32 degrees?

Pedals

2.6. Equal angles?

2.7. Range of angles $<25$ degrees?

Dashboard

2.8. Uniform design of dashboards of buses?

2.9. Easily accessible?

2.10. User-friendly?

2.11. Clear colours?

Working space

2.12. Enough working space?

2.13. Effective heating and cooling systems?

2.14. Are the drivers trained in the use of cabin components?

\section{Work and rest schedules and timetable}

3.1. Is there enough time to drive safely, according to the schedule, and provide service to the passengers?

3.2. Is work organized in periods of several (maximum 4) consecutive days within the same shift?

3.3. Are split shifts avoided?

3.4. Are assignments on a regular basis?

3.5. Are shifts in forward rotation: early-day-late?

3.6. Are days off in twos instead of single days?

3.7. Are there guaranteed opportunities to take days off?

3.8. Is there a 20 -min break following every 2 working hours?

4. Social work environment

4.1. Is the total driving staff divided into fixed groups?

4.2. Is there an effective system of work consultation?

4.3. Is there a supportive style of leadership?

4.4. Are there opportunities for (re)education?

4.5. Are there special facilities for older drivers and for drivers with health problems?

4.6. Is there a timely and active rehabilitation policy?

4.7. Are individual resumption plans worked out?

4.8. Is there a clear management style?

4.9. Are non-work contacts promoted?

4.10. Is a corporate identity stimulated?

4.11. Is there a proper information flow in the company?

4.12. Are wishes of individual drivers taken into account?

4.13. Can drivers be replaced during illness?

4.14. Are canteen facilities good?

4.15. Are vacancies quickly filled?

Note: The amount of 'no' scores should be as low as possible. The higher the scores on each of the four subscales, the greater the number of problems. Individual attention should be paid to every 'no' answer. 
Table 6-Ten hints for organizational change

1. Promote commitment and participation from all 'parties'. This will take time and demands continuous effort. But it is worthwhile!

2. Spend time beforehand on the ways in which transfer of information ought to take place.

3. Maintain period feedback as the project proceeds. Take time for discussing these developments

4. Promote trust and cooperation between different parties. Maintain good personal contacts

5. Present several interventions in a systematic order. Give people time to accommodate to change

6. Create a proper technical preparation of measures. Technical and organizational mistakes might undermine trust in the final results

7. Try to 'score' one or two points at the beginning. Such results often have a symbolic value and can be an impetus for further positive change

8. 'Key persons' in the company, formal and informal leaders, should 'give the right example', eg taking part in a training programme

9. Pay attention to the position of lower and middle management. Often these groups play a crucial role in the process of organizational change

10. Give employees the opportunity to influence changes

Table 6 specifies some 'golden rules' that are especially useful in this step, but also in the other steps.

\section{Step 5: Evaluation (including costs and benefits)}

This final step should provide information about the effectiveness of the measures and indicate if additional measures are needed. A proper evaluation also addresses the financial costs and benefits of the project. It is important that consideration of work stress is no 'one-time' event. Attention to the quality of working life should be - and continue to be - part of the daily management routine of every company.

Naturally this stepwise approach is an 'ideal' one. Organizational change is hard to manage. In practice, consecutive steps will be mixed to some extent. However, these five steps, combined with a continuous focus on organizational commitment, form the backbone of a successful stress prevention approach.

There are indications that those companies that invest in preventive measures receive their rewards. These range from a better management-labour relationship, better morale among the staff and better service to the public to less turnover, less absenteeism and less work disability.

\section{REFERENCES}

1. Anderson, R. The back pain of bus drivers: Prevalence in an urban area of California. Spine 1992; 17(12): 1481-1488.
2. Aronsson, G. Sickness absence for local public transport personnel at Stockholm transport. University of Stockholm, Stockholm, report no. 33, 1982.

3. Backman, A. L. Health survey of professional drivers. Scand. J. Work. Environ. Health 1983; 9: 30-35.

4. Brooks, B. M. An investigation into aspects of bus design and passenger requirements. Ergonomics 1979; 22: 175-188.

5. Courtney, A. J. and Wong, M. H. Anthropometry of the Hong Kong male and the design of bus driver cabs. Appl. Ergonom. 1985; 16: 259-266.

6. Davis, G. N. and Lowe, T. J. The ergonomic London bus. In: Contemporary Ergonomics 1987. Megaw, E. D. (Ed.) Taylor \& Francis, London 1987. pp. 179-184.

7. Duffy, C. A. and McGoldrick, A. E. Stress and the bus driver in the UK transport industry. Work Stress 1990; 4: 17-27.

8. Erlam, A. R. Sickness absence in drivers of London taxis and buses. J. Soc. Occup. Med. 1982; 32: 20-25.

9. Feickert, D. and Forrester, K. Stress factors in urban public transport. Working Environment Research Group, University of Bradford, Report on the Conference 'Working Environment in Urban Public Transport', Stockholm, 1983.

10. Felnemeti, A. and Boon-Heckl, U. Belastungsuntersuchung an Salzburger Busfahrern. Z. Verkehrssicherheit 1985; 31: 16-21.

11. Garbe, C. Ansatze betrieblicher Epidemiologie am Beispiel der Untersuchung gesundeheitlicher Selectionsprozesse bei Busfahrern. Report on the Conference 'Working Environment in Urban Public Transport', Stockholm, 1983.

12. Gardell, B., Aronsson, G. and Barklof, K. The working environment for local public transport personnel. Report from the Swedish Work Environment Fund, 1982. 
13. Grosfeld, J. A. M. Work quality and absenteeism (in Dutch). In: Prevention and Reduction of Absenteeism in Bus Drivers (in Dutch). Boelman, M. (Ed.) Project Reduction of Absenteeism, Nijmegen, 1993, pp. 27-52.

14. De Haan, Onland and Brokerhof. Work Absenteeism Among Bus Drivers in Amsterdam (in Dutch). Amsterdam, 1978.

15. Holme, I., Helgelund, A., Hjermann, I., Leren, P. and Lund-Larsen, $P$. Coronary risk factors in various occupational groups: The Oslo study. Brit. J. Prev. Soc. Med. 1977; 31: 96-100.

16. Kompier, M. A. J. Work and Health of city bus drivers (in Dutch). Doctoral thesis. Eburon, Delft, 1988.

17. Kompier, M. A. J. A literature review on work and health of city bus drivers (in Dutch). University of Groningen, Groningen, Research report, 1985.

18. Meifort, J., Reiners, H. and Schuh, J. Arbeitsbedingungen von Linienbus-, und Strassenbahnfahrern. Bundesanstalt fur Arbeitsschutz und Unfallforschung, Dortmund No. 33 Schriftenreihe Arbeitsschutz, 1983.

19. Meijman, T., Linden, T., van der, Mulders, H., Bussel, M. van and Steensma, L. Effects in the development of continuous workload and insuffcient recovery in bus drivers in Groningen (in Dutch). In: Work and Health: Absenteeism and the Quality of Working Life (in Dutch). Vrooland, V. (Ed.) Alphen aan de Rijn, Samsom, 1982.

20. Morris, J. N., Kajan, A., Pattison, D. C. and Gardiner, M. J. Incidence and prediction of ischaemic heart disease in London busmen. Lancet 1966; Sept., 553-559.

21. Mulders, H., Meijman, T. F., O'Hanlan, J. and Mulder, G. Differential psychophysiological reactivity of bus drivers. Ergonomics 1982; 25: 1003-1011.

22. Netterstrom, B. and Laursen, P. Incidence and prevalence of ischaemic heart disease among urban bus drivers in Copenhagen. Scand. J. Soc. Med. 1981; 9: 75-79.

23. Nijhuis, F. J. N. and Bullinga, R. Prevention: Improve the worksite and work organization (in Dutch). Gedrag \& Organisatie 1991; 19: 36-39.

24. Oortman-Gerlings, P., Drimmelen, D. van and Musson, Y. Whole body vibration: Results of empirical measurements (in Dutch). Leidschendam, LA-DR-10-04, 1985.

25. Oversloot, J., Dijkstra, A., Grinten, M. van der, Schlatmann, M. and Winter, C. de. Work and Health: Busdrivers in Rotterdam (in Dutch). Nederlands Instituut voor Praeventieve Gezondheidszorg, Leiden, 1982.

26. Pikus, W. G. and Tarannikova, W. A. Hypertensive disease incidence in drivers of passenger motor transport. Ter. Arch. 1975

27. Pokorny, M. L. I., Blom, D., Leeuwen, P. van and Nooten, W. van. Shift sequences, duration of rest periods, and accident risk of bus drivers. Hum. Factors 1987; 29: 73-81.

28. Ragland, D. R., Winkleby, M. A., Schwalbe, J. et al. Prevalence of hypertension in bus drivers. Int. J. Epidemiol. 1987; 16: 208-214.

29. Reimann, J. Beanspruchung von Linien Busfahrern. Bundesanstalt fur Arbeitsschutz und Unfallforschung, Dortmund, 1981. Forschungsbericht, no. 271.

30. Rissler, A. and Aronsson, G. Stressors, psychophysiological reactions and health complaints among urban bus drivers. Report on the Conference 'Working Environment in Urban Public Transport', Stockholm, 1983.

31. Rusconi, C., Arosio, G., Orlando, G., Petroboni, V., Riva, S., Gola, G. et al. Fattori di rischio coronarico e cadiopatia ischeamica nei conduttori e nei bigliettari di autobus. Minerva Cardioangiol. 1975; 23: $718-727$.

32. Winkleby, M. A., Ragland, D. R., Fisher, J. M. and Syme, S. L. Excess risk of sickness and disease in bus drivers: A review and synthesis of epidemiological studies. Int. J. Epidemiol. 1988; 17: 255-262.

33. Bailer, H. and Trankle, U. Mischarbeit mit dem Ziel der Verringerung von Belastungen und Beanspruchungen: Uberlegungen am Beispiel Fahrtatigkeiten im offentlichen Personennahverkehr. Z. Arb-Organizationspsychol. 1994; 38: 126-130.

34. Linden, J. van der. Work stress: The approach by HTM, The Hague (in Dutch). Conference on Working Conditions, April 1992, Maastricht.

35. Hamelink, J., Linde, N. van der and Taylor, J. Company physical fitness (in Dutch). In: Prevention and Reduction of Absenteeism in Bus Drivers (in Dutch). Boelman, M. (Ed.) Project Reduction of Absenteeism, Nijmegen, 1993.

36. Hammecher, L., Joppen, R. and Plug, S. Stress management at GSM (in Dutch). In: Prevention and Reduction of Absenteeism in Bus Drivers (in Dutch). Boelman, M. (Ed). Project Reduction of Absenteeism, Nijmegen, 1993, pp. 149-171.

37. Walt van Praag, W. A. van. Work behaviour, muscular tension, and sit instruction (in Dutch). In: Prevention and Reduction of Absenteeism in Bus Drivers (in Dutch). Boelman, M. (Ed). Project Reduction of Absenteeism, Nijmegen, 1993, pp. 84-111.

38. Kompier, M. A. J. and Marcelissen, F. H. G. Handbook Work Stress (in Dutch). Nederlands Instituut voor Arbeidsomstandigheden, Amsterdam, 1990.

39. Karasek, R. A. Stress prevention through work reorganization: A summary of 19 international case studies. In: Preventing Stress at Work. Di Martino, V. (Ed.) Conditions of Work Digest, 11, 2. ILO, Geneva, 1992.

40. Kompier, M. and Levi, L. Stress at Work: Causes, Effects and Prevention. Guide for Small and MediumSized Enterprises. European Foundation for the 
Improvement of Living and Working Conditions, Dublin, 1994.

41. Levi, L. Stress in Industry - Causes, Effects and Prevention. International Labour Office, Geneva, 1984.
42. Boelman, M. (Ed.) Prevention and Reduction of Absenteeism in Bus Drivers (in Dutch). Project Reduction of Absenteeism, Nijmegen, 1993. 